\title{
4D corneal tissue engineering: achieving time-dependent tissue self-curvature through localized control of cell actuators
}

Article

Accepted Version

Miotto, M., Gouveia, R. M., Ionescu, A. M., Figueiredo, F., Hamley, I. W. and Connon, C. J. (2019) 4D corneal tissue engineering: achieving time-dependent tissue self-curvature through localized control of cell actuators. Advanced Functional Materials, 29 (8). 1807334. ISSN 1616-3028 doi: https://doi.org/10.1002/adfm.201807334 Available at https://centaur.reading.ac.uk/81712/

It is advisable to refer to the publisher's version if you intend to cite from the work. See Guidance on citing.

To link to this article DOI: http://dx.doi.org/10.1002/adfm.201807334

Publisher: Wiley

All outputs in CentAUR are protected by Intellectual Property Rights law, including copyright law. Copyright and IPR is retained by the creators or other copyright holders. Terms and conditions for use of this material are defined in the End User Agreement. 


\section{CentAUR}

Central Archive at the University of Reading

Reading's research outputs online 
4D Corneal Tissue Engineering: Achieving Time-Dependent Tissue Self-Curvature through Localized Control of Cell Actuators

Martina Miotto, Ricardo M. Gouveia, Ana M. Ionescu, Francisco Figueiredo, Ian W. Hamley and Che J. Connon*

Dr. M. Miotto, Dr. R.M. Gouveia, Prof. F. Figueiredo and Prof. C.J. Connon

Institute of Genetic Medicine, Newcastle University, International Centre for Life, Central Parkway, Newcastle upon Tyne, NE1 3BZ, United Kingdom

Prof. F. Figueiredo

Department of Ophthalmology, Royal Victoria Infirmary, Queen Victoria Road, Newcastle upon Tyne, NE1 4LP, United Kingdom

Prof. I.W. Hamley

School of Chemistry, Food and Pharmacy, University of Reading, Whiteknights, Reading RG6 6UB, United Kingdom

Dr. A.M. Ionescu

Departamento de Óptica, Facultad de Ciencias, Universidad de Granada, Avenida de la Fuente Nueva S/N C.P. 18071, Granada, Spain

Prof. C.J. Connon

E-mail: Che.Connon@newcastle.ac.uk

Keywords: 4D tissue engineering, bio-actuators, cell-driven tissue curvature, peptide amphiphiles, artificial corneal stroma 
Abstract

While tissue engineering is widely used to construct complex tridimensional biocompatible structures, researchers are now attempting to extend the technique into the fourth dimension. Such fourth dimension consists in the transformation of 3D materials over time, namely by changing their shape, composition, and/or function when subjected to specific external stimuli. In this study, we instead explored producing a 4D biomaterial with an internal mechanism of stimulus, using contractile cells as bio-actuators to change tissue shape and structure. Specifically, we aimed at producing cornea-shaped, curved stromal tissue equivalents via the controlled, cell-driven curving of collagen-based hydrogels. This was achieved by modulating the activity of the bio-actuators in specific, delimited regions of the gels using a contraction-inhibiting peptide amphiphile. The selfcurved constructs were then characterized in terms cell and collagen fibril re-organization, gel stiffness, cell phenotype, and the ability to sustain the growth of a corneal epithelium in vitro. Overall, our results showed that the structural and mechanical properties of self-curved gels acquired through a 4D engineering method were more similar to those of the native tissue, and represented a significant improvement over planar 3D scaffolds. In this perspective, this study demonstrates the great potential of cell bio-actuators for 4D tissue engineering applications. 


\section{Introduction}

In the past few decades, considerable efforts have been made to engineer new biomaterials that successfully emulate the complex three-dimensional (3D) organization of human tissues in order to better replace them. These 3D tissue equivalents are commonly comprised of natural or synthetic components designed to reproduce the structure and mechanics of native extracellular matrix (ECM) and provide suitable biochemical and biophysical cues for supporting the adhesion, growth, and survival of specific cell types. ${ }^{[1]}$ Recently, a greater attention has been given to the development of smart biomaterials that can reversibly or irreversibly change shape, size, texture, or composition through time and in response to internal programs and/or external stimuli (e.g., temperature, $\mathrm{pH}$, current, osmotic pressure, light). ${ }^{[2,3]}$ Some of these so-called 4D biomaterials are designed as synthetic cell scaffolds that change their intrinsic properties upon a specific stimulation, ${ }^{[4,5]}$ usually aiming at improving cell behavior and/or tissue function post-implantation. Other 4D approaches focus instead on exploring living cells as the force generators to drive changes in their supporting scaffolds. $^{[6,7]}$ In particular, sheets of contractile cardiomyocytes ${ }^{[8]}$ or skeletal muscle cells ${ }^{[9]}$ have been used as bio-actuators to promote the rapid and dynamic shape-change of elastomer frames and produce motion. However, and to our present knowledge, cells have not yet been used as bioactuators to improve the function of 4D-engineered biological tissue equivalents.

In particular, we were interested in using such bio-actuator systems to produce curved collagen gels that could recreate the shape of the human cornea. This outermost tissue of the eye is comprised of a dense collagen stroma, where shape, composition, and ultra-structural organization all play a closely integrated and crucial role in maintaining the tissue's strength, transparency, and ability to refract light. ${ }^{[10-14]}$ Previous attempts to recreate this functionally complex tissue have tried to address different challenges by adopting either top-down or bottom-up tissue engineering strategies. For example, top-down approaches typically combined cells with cornea-shaped matrices fabricated via molding, ${ }^{[15]}$ electrospinning, ${ }^{[16]} 3 \mathrm{D}$ bio-printing, ${ }^{[17]}$ or mechanical $\operatorname{strain}^{[18]}$ to rapidly produce transplantable tissues. ${ }^{[19,20]}$ However, these tissues have demonstrable limitations in terms of 
recreating the important ultrastructural and compositional properties of the tissue, such as the lamellar organization of the matrix, the dimension, density, and alignment of collagen fibrils, and the ratio between different ECM components. ${ }^{[21]}$ In contrast, bottom-up approaches have allowed the bio-fabrication of more native-like tissues in terms shape, ${ }^{[22]}$ ultrastructure, ${ }^{[23-25]}$ and composition ${ }^{[23,24,26,27]}$, but these methods are slower and still unable of producing full-thickness corneas.

In previous studies, we explored potential methods to improve the function of corneal stromal equivalents, namely by modulating the contractile activity of stromal cells incorporated within 3D collagen scaffolds through the addition of a bio-functional peptide amphiphile (PA). ${ }^{[28]}$ Briefly, we created collagen hydrogels combined with a PA comprising the cell-binding RGDS peptide motif to provide a preferential adhesion cue for human corneal stromal cells (hCSCs). Subsequently, these PA-collagen composite scaffolds were shown to contract less than their collagen-only counterparts, with the PA inhibiting the contractile activity of hCSCs via specific RGDS-integrin interactions. ${ }^{[28]}$ This important finding allowed us to devise a new 4D tissue engineering system, whereby hCSCs can promote tissue self-curvature through the precise spatial distribution of their bio-actuator activity. Specifically, we used the hCSC-adhesive $\mathrm{C}_{16} \mathrm{G}_{3}$ RGDS $\mathrm{PA}^{[29]}$ to program the trajectories of cell contraction in well-defined regions of compressed collagen gels (CCGs) and create strain differentials similar to those observed during the morphogenesis of dome-shaped tissues. ${ }^{[30]}$ Interestingly, the resulting tissues not only achieved a cornea-shaped curvature but also presented a more native-like ultrastructure and composition, with self-curved tissues evidencing higher cell and ECM organization and improved bio-function. Overall, this study illustrates the considerable potential impact of PA functionalization and cell bio-actuators in 4D tissue engineering, particularly for the production of improved corneal stromal equivalents. 


\section{Results and Discussion}

\subsection{Cell-Driven Contraction of Compressed Collagen Gels can be Modulated with PA}

The ability to use human corneal stromal cells (hCSCs) as tunable bio-actuators was tested by evaluating the impact of cell density and medium composition on collagen gel contraction. Specifically, hCSCs were encapsulated uniformly within compressed collagen gels (CCGs) either at low (LCD) or high cell density $(\mathrm{HCD})\left(0.9\right.$ or $1.8 \times 10^{5}$ cells per $\mathrm{mL}$ of collagen solution, respectively) and cultured for 7 days in the absence (SFM) and presence of serum (+FBS). Results showed a significant $(p<0.0001)$ and time-dependent decrease in gel size for all conditions due to cell-driven contraction (Figure 1a). The highest CCG contraction was observed for HCD and +FBS culture conditions. The presence of serum in particular drastically contributed to CCG contraction, with HCD and LCD gels in + FBS medium at day 7 contracting to $12 \pm 3$ and $23 \pm 6 \%$ of their initial size, respectively. This corresponded to a significant $(p<0.001) 2.3$ - and 1.8-fold increase in contraction over HDC and LCD gels in SFM (50 \pm 2 and $67 \pm 3 \%$ of initial size, respectively) (Figure 1a). These differences were expected, as serum has been shown to activate hCSCs toward a contractile, myofibroblast-like phenotype. ${ }^{[31]}$ In contrast, cell density showed to have a more limited (albeit still significant) impact on CCG contraction, with HDL in +FBS and SFM inducing a significant 1.1- and 1.5-fold increase in gel contraction compared to their LCD counterparts $(p=$ 0.026 and 0.013, respectively) (Figure 1a).

Likewise, the ability to modulate hCSC-driven gel contraction using the self-assembled $\mathrm{C}_{16} \mathrm{G}_{3} \mathrm{RGDS}$ peptide amphiphile (PA) within CCGs was evaluated. Specifically, the inhibitory effect of PA in CCG contraction was investigated by culturing cell-encapsulated, compressed PA/collagen gels (+PA) for 7 days in +FBS and SFM conditions. CCGs without PA (-PA) or without cells were used as positive and negative contraction controls, respectively. CCGs containing PA (+PA) showed significantly lower contraction compared with gels without it (-PA), both in + FBS (up to day 5, $p=0.042$ ) (Figure 1b) and SFM conditions (from day 2 onwards, $p=$ 
0.039) (Figure 1c). Furthermore, +PA gels showed no significant reduction in size compared to CCGs without cells (no cell control) both in +FBS (up to day 3) (Figure 1b) and SFM conditions (during the entire culture period) (Figure 1c). The ability of PA to inhibit CCG contraction was similarly observed in previous studies using the Fmoc-RGD functionalizing molecule, ${ }^{[28]}$ then attributed to the preferential binding of cells to the adhesion peptide. Together, these results demonstrate that hCSCs have the ability to contract CCGs in a time-dependent manner, and that this bio-actuator activity can be modulated by different cell density, medium conditions, and collagen gel functionalization using a PA.

\subsection{Defined PA Localization within Composite CCGs Allows Tissue Self-Curvature}

Having demonstrated that hCSCs could be controlled to function as bio-actuators, we designed and produced composite CCGs, with PA limited to either the center (inner-PA) or periphery (outer-PA) of the gels (Figure 2a). We hypothesized that the presence of PA would decrease the rate of gel contraction within a limited area of the CCGs, and consequently create a contraction differential between the gels' center and periphery that would result in tissue shape change. Composite CCGs 120-150 $\mu \mathrm{m}$ thick were thus cultured for up to 7 days either in +FBS or SFM. Interestingly, both inner-PA and outer-PA composite gels showed a gradual shape change when in +FBS condition (Figure 2b), visibly increasing their curvature over the course of the culture period (Video 1; Video

2). The direction of this curvature was independent of PA localization, with both inner-PA and outer-PA equally contracting into convex and concave cornea-shaped tissues (Figure 2c). This effect further indicated that gel curvature was not gravity-driven, but the result of a change in the intrinsic structure of the gels via actuation by the highly viable hCSCs (Figure 2d). Curvature directionality may depend on stochastic distribution of hCSCs, with higher cell density on the top or the bottom of the gels leading to concave or convex curvature, respectively. After 5 days in culture, the curvature angle of composite CCGs reached a plateau of approximately $25^{\circ}$ (Figure 2e), a shape similar to that of the native cornea. Beyond the fifth day in +FBS culture, gels continued to 
contract and lost their distinct cornea-like shape whilst maintaining high cell viability, both in the center and periphery of the gels (Figure 2d). In contrast, gels in SFM maintained their initial planar shape (Figure $\mathbf{2 b}$ ) despite their mild contraction and the high viability of their encapsulated cells (Figure 2d).

\subsection{The Contractile Phenotype of hCSCs in Self-Curved CCGs}

The effect of the different culture conditions on the contractile phenotype of encapsulated hCSCs was evaluated by in-cell Western blotting. This approach allowed us to compare the total amount of protein and its relative distribution across the constructs simultaneously. Firstly, the expression of the $\alpha$-smooth muscle actin ( $\alpha$ SMA) contraction marker was quantified in self-curved and planar CCGs after 5 days in +FBS and SFM, respectively, by near-infrared fluorescence analysis. Protein expression was also distinguished between the regions of tissues with (+PA) or without PA (-PA). Ostensibly, self-curved CCGs showed higher aSMA expression compared to planar gels (Figure 3a). This was an expected outcome, since hCSCs in +FBS conditions are known to acquire a contractile phenotype dependent on $\alpha$ SMA stress fibers, ${ }^{[32]}$ whereas SFM keeps cells in a quiescent, non-contractile state by preventing the formation of such fibers. ${ }^{[33]}$ However, no significant differences in $\alpha \mathrm{SMA}$ expression were shown between +PA and -PA areas of composite CCGs (Figure 3a). This result was surprising in view of the PA's strong inhibitory effect on gel contraction previously observed (Figure 1), and suggested that its modulating activity was not exerted via direct regulation of cell phenotype. This notion was supported by the levels of $\alpha \mathrm{V} \beta 5$ integrin and keratocan (markers of activated ${ }^{[34]}$ and quiescent hCSCs, ${ }^{[35]}$ respectively), both of which were not altered by the presence of PA, either in +FBS or SFM conditions (Figure 3b). Instead, the PA probably acted by providing a ligand within the structural collagen matrix to which cells preferentially adhered (i.e. a scaffold-within-a-scaffold). ${ }^{[28]}$ As collagen fibrils forming the main structural component of our composite CCGs were not chemically cross-linked to the PA, this allowed PA-bound cells to freely contract while exerting a reduced actuation on the overall shape 
and density of the tissue. Taken together, these results further support the concept of CCG selfcurvature being induced by the localized contractile activity of myofibroblast-like hCSCs, with PA preventing, in part, the action of such contractile cells on the collagen gel matrix.

\subsection{Self-Curvature Induces Cell and ECM Reorganization}

Confocal microscopy was used to evaluate the organization of hCSCs encapsulated in inner-PA and outer-PA CCGs cultured either in +FBS or SFM (Figure 4). Specifically, composite CCGs were collected every day, up to day 5 of culture (the time necessary to achieve a homogeneous curvature in +FBS conditions), and then fixed, and incubated with phalloidin (to image the actin cytoskeleton) and anti-collagen I antibody. Both types of self-curved CCGs (inner-PA and outer-PA) showed increasing organization of hCSC throughout the culture period, with cells gradually assuming higher degrees of alignment over time (Figure 4; Figure S2). Specifically, cells encapsulated within self-curved CCGs displayed a more uniform orientation after 5 days in culture, with orthogonal-like alignment in both their center and periphery regions (Figure 4, self-curved gels). In contrast, cell orientation within planar CCGs (cultured in SFM) was mostly random (Figure 4, planar gels). Interestingly, hCSCs within 200-300 $\mu \mathrm{m}$ of the outer edges of the CCGs showed a uniform circumferential alignment independent of the culture condition (Figure S2). This alignment was likely related to a boundary effect initiated by the compression method, as suggested by the similar edge-parallel cell orientation immediately after compression of square-shaped collagen gels (Figure S1). Together, these results indicated that self-curved 4D tissues promoted a more organized cell alignment and distribution, starting after the first day in +FBS and progressing throughout the period in culture. This suggested that hCSC orientation changed in response to the cell-driven, PA-modulated tissue self-curvature and not vice versa, i.e. bio-actuation induced cell reorganization and alignment along with CCG contraction into a cornea-like shapes. This notion was supported by the cell-orientation effects observed in corneal stroma models subjected to equibiaxial strain. ${ }^{[18]}$ But most importantly, the orientation of hCSCs within self-curved 4D tissues, 
and particularly their orthogonal alignment in the center, had a striking similarity to that of cells in the native corneal stroma. ${ }^{[36]}$

The orientation of the collagen fibrils comprising the various CCGs was analyzed using atomic force microscopy (AFM). Specifically, the surface topography of self-curved (+FBS) inner-PA and outer-PA gels was evaluated and compared with that of planar (SFM) tissues. Similarly to what was observed for encapsulated hCSCs, collagen fibrils from self-curved CCGs were shown to acquire a more regular orientation over time (Figure 5a, day 1 versus day 5), with highly aligned, orthogonaloriented fibrils forming a relatively smooth surface topography in both center and periphery regions after 5 days in + FBS culture (Figure 5b). Conversely, planar gels showed to be comprised by randomly oriented collagen fibrils with a rougher topography and less organized collagen fibrils (Figure 5) similar to that of CCGs without encapsulated cells (Figure S3). These results supported the notion that contracting hCSCs acted on the matrix components of CCGs (presumably via cellcollagen interactions), ${ }^{[37]}$ and that the constant and progressive biomechanical tension exerted was instrumental for collagen fibril stretching, ${ }^{[38]}$ ECM reorganization ${ }^{[39,40]}$ and tissue self-curvature over time. In contrast, the lack of contracting hCSCs in SFM conditions allowed collagen fibrils to remain randomly orientated, relaxed, and to maintain a planar CCG matrix.

\subsection{Self-Curvature Modulates the Mechanical Properties of CCGs}

The mechanical properties of the different constructs were evaluated by force-distance atomic force microscopy, probing distinct areas of the gels. A consistent increase in elastic modulus over time in culture (i.e. from day 1 to day 4) was observed in both the center and periphery of inner-PA and outer-PA CCGs in +FBS conditions (Figure 6a), with self-curved CCGs showing an overall higher stiffness compared to their correspondent planar tissues (SFM) (Figure 6b). The higher elastic modulus of CCGs in the presence of serum was expected, as the activation of hCSCs (and consequently their function as bio-actuators) was the force driving gel contraction (Figure 1) and increasing collagen fibril organization (Figure 5). Moreover, increased CCG stiffness corresponded 
to lower gel hydration (Figure S4). The correlation between increased stiffness and higher contraction/increased matrix organization/reduced hydration is well-documented in collagen-based hydrogels. ${ }^{[41]}$ Interestingly, in +FBS conditions the regions of CCGs containing PA (periphery and center for outer-PA and inner-PA, respectively) were significantly softer compared to their counterparts without PA (Figure 6, red versus black dots). This lower stiffness likewise corresponded to higher gel hydration (Figure S4). The impact of PA on the mechanical properties of gels was also observed in composite CCGs cultured in SFM, but in a much lesser degree (Figure 6b). This difference suggested that the PA did not influence CCG stiffness by directly affecting the collagen cross-linking. This notion is supported by the similar mechanical properties between the different regions of gels at day 1 (Figure 6b), as well as by the slightly higher hydration of PAcontaining regions of CCGs (Figure S4).

\subsection{Effects of Self-Curvature on Corneal Epithelial Cell Growth and Phenotype}

The diverse mechanical properties between center and periphery of self-curved composite CCGs (softer in $+\mathrm{PA}$ and stiffer in -PA regions) led us to investigate how these features impacted the growth of human limbal epithelial stem cells (hLESCs). Previous studies have shown that differences in tissue topography and/or compliance can regulate the phenotype of these cells, with more organized, stiffer collagen-based substrates promoting hLESC differentiation, ${ }^{[22,23]}$ probably though mechanotransduction signaling pathways. ${ }^{[42,43]}$ Since the human corneal epithelium requires the support of a well-ordered native stroma in order to maintain its homeostasis, ${ }^{[4]}$ our experiment aimed at demonstrating the suitability of self-curved CCGs to serve as substrate for the adhesion, growth, and differentiation of hLESCs. To this purpose, hLESCs were seeded onto the periphery of self-curved inner-PA or outer-PA CCGs and grown on the gels' convex side for 10 days in a liquid environment (Figure 7a). Results showed that hLESCs were able to attach, migrate, and proliferate across the entire surface of the gels (Figure 7a). Subsequently, the effects of the different mechanical properties of their substrate were evaluated through the expression analysis of $\Delta \mathrm{p} 63$ 
(stem/progenitor cell marker), ${ }^{[45]} \mathrm{CK} 3$ (differentiation marker), ${ }^{[46]}$ and YAP, a transcription factor whose nuclear localization has been associated with cell differentiation via mechanosensing. ${ }^{[47]}$ Results showed that hLESCs on the periphery of inner-PA gels (more organized, stiffer matrix) expressed significantly reduced levels of the stem/progenitor cell marker $\Delta \mathrm{p} 63(p=0.0012)$ compared to cells growing in the center (Figure $7 \mathbf{b}$ ). In addition, cells on the periphery showed YAP predominantly located in the nucleus $(p=0.009$; Figure $7 \mathbf{b})$, a known hLESC response to stiff substrates. ${ }^{[42]}$ This was reversed in cells grown on the center region of inner-PA CCGs (Figure 8b), with the significantly lower nuclear YAP levels $(p=0.0015)$ indicating a change in cell mechanosensing due to higher compliance of the substrate (Figure 6a). This change was also accompanied by a significantly lower expression of the differentiation marker CK3 $(p=0.0001)$ in hLESCs grown on the center of inner-PA CCGs (Figure 7b), a decrease previously shown to be associated with lower substrate stiffness. ${ }^{[43]}$ Consistently, hLESCs grown on outer-PA gels showed the reverse expression pattern (Figure 7c), with cells on the center (stiffer matrix) expressing significantly lower levels of $\Delta \mathrm{p} 63$ and cytoplasmic YAP ( $p=0.003$ and 0.0001 , respectively) as well as higher levels of nuclear YAP and CK3 ( $p=0.022$ and 0.011 , respectively) compared to those on the periphery region (Figure 7c). Together, these results demonstrated that the PA can locally modulate hCSC adhesion and their function as bio-actuators, to subsequently produce selfcurving tissues with specific and localized structural (Figure 5), mechanical (Figure 6), and biological properties (Figure 7). Such self-curved CCGs provided a suitable surface for the attachment and growth of hLESCs, with outer-PA gels allowing cells to remain undifferentiated in their (softer) periphery while becoming more differentiated their (stiffer) center. This is important, as such biomechanical and bio-functional properties reproduced those of the native tissue, with undifferentiated hLESCs located in the softer limbus and the differentiated epithelium spanning the stiffer center of the anterior cornea (Eberwein et al, 2014).

\section{Conclusion}


This study demonstrated the possibility to create shape-changing tissues by incorporating bioactive PA nanostructures to modulate cell-driven contraction within their matrix. Such self-curved tissues thus represented a new and improved model of the human corneal stroma, combining both topdown (i.e., the fabrication of cell-populated CCGs) and bottom-up tissue engineering approaches (i.e., the cell-driven alteration of the scaffolds). Ultimately, these cornea-shaped tissues displayed better cell and ECM organization compared to their planar counterparts. The influence of the bioactive PA was also extended to the tissues' mechanical properties, which in turn allowed the creation of delimited biomechanical niches on their surface as well as the modulation of hLESC growth and differentiation. Specifically, the stem cell-like phenotype of hLESCs was better supported by tissue regions containing PA, probably due to their lower elastic modulus. In contrast, tissue regions without PA and subject to increased cell actuation and contraction provided a stiffer matrix that promoted epithelial differentiation. The ability to use PAs to modulate the shape and stiffness of collagen-based biomaterials via the control of cell actuators is a particularly useful tool in 4D tissue engineering, and can thus be translated into a broad range of applications. For example, PAs could be used to rationally design more complex composite materials where structural, biomechanical, and bio-functional properties can evolve towards emulation of a specific native tissue. As such, 4D tissue equivalents not only have the potential to revolutionize tissue engineering and regenerative medicine strategies, but also can contribute to a more fundamental understanding of the mechanisms underlying tissue and organ morphogenesis. 


\section{Experimental Section}

Human Corneal Cell Isolation and Culture: Human corneal stromal cells (hCSCs) and human limbal epithelial stem cells (hLESCs) were isolated from cadaverous human corneal tissue (donors' age between 40 and 78; average \pm S.D. $=59 \pm 11$ years, male-female donor ratio of 2:3, with no prior history of corneal diseases or ocular trauma). All human corneas were collected from NHS Blood and Transplant (NHSBT) via a service level agreement with Newcastle-upon-Tyne Hospitals NHS Foundation Trust, UK. All donors approved the use in research of their corneal tissues, in full accordance with the regional ethics committee approval and research agreement. Briefly, each corneal ring was gently scraped to remove the endothelium, cut radially in 6 pieces of equivalent size, individually placed in 6-well plate (Greiner Bio-One, Austria) with the epithelium-side facing the bottom of the well and cultured for 10 days in $4 \mathrm{~mL}$ of CnT-7 medium (CellNTec, Switzerland) at $37^{\circ} \mathrm{C}$, in humidified and $5 \% \mathrm{CO}_{2}$ cell culture incubator conditions. Subsequently, the corneal pieces were removed while the epithelial cells previously shed by the tissues during culture were enzyme-dissociated from the plate surface with StemPro Accutase (Thermo Scientific, MA, USA) for $10 \mathrm{~min}$ and passaged for expansion in tissue culture flasks (Greiner Bio-One) with CnT-7 medium. Media were replaced every 2 days following a gentle wash with phosphate buffered saline (PBS) (Thermo-Scientific) and hLESCs were used for subsequent experiments up to the second passage. Corneal pieces were further used to extract hCSCs. Briefly, corneal tissues were minced using a scalpel, transferred to DMEM/F12 medium (Thermo Scientific) supplemented with 5\% fetal bovine serum (FBS) (BioSera, France), $2 \mathrm{~g} \mathrm{~L}^{-1}$ (450 units $\mathrm{mL}^{-1}$ ) collagenase type-1 (Thermo Scientific) and incubated at $37^{\circ} \mathrm{C}$ in a humidified, $5 \% \mathrm{CO}_{2}$ incubator under continuous rotation for 5 $\mathrm{h}$, followed by incubation with $0.25 \%$ trypsin-EDTA (Thermo Scientific) for $10 \mathrm{~min}$. The isolated hCSCs were collected and plated onto tissue culture flasks and maintained using serum-containing medium (+FBS) comprising DMEM/F12 medium supplemented with 5\% FBS and 1\% penicillin/streptomycin (Thermo Scientific), with medium changed every 2-3 days, and cultures maintained until reaching $70-80 \%$ confluence. Cells were then serum-starved for three days in 
serum-free medium (SFM) comprising DMEM/F12 with $1 \times 10^{-3} \mathrm{M}$ ascorbic acid (Sigma Aldrich, MO, USA), $1 \times$ ITS (Sigma Aldrich), and 1\% penicillin/streptomycin to induce quiescence. Cells were detached using TrypLETM express enzyme (Thermo Scientific) and encapsulated in collagen gels. Each experiment was performed thrice using hCSCs up to passage 5, from three different donors.

Preparation of Peptide Amphiphiles: The $\mathrm{C}_{16} \mathrm{G}_{3} \mathrm{RGDS}$ peptide amphiphile (PA) was customsynthesized by CS Bio (Menlo Park, CA, USA) as $>95 \%$ pure trifluoroacetic acid salts and its molecular weight $\left(842.95 \mathrm{~g} \mathrm{~mol}^{-1}\right)$ confirmed by electrospray-mass spectrometry. ${ }^{[48]}$ The PA was then weighted and solubilized in SFM at $5 \mathrm{mM}$ and stored at $4^{\circ} \mathrm{C}$ until added to the collagen gel solution in a 1:10 ratio.

Preparation of Compressed Collagen Gels: Functionalized constructs were prepared by combining PA with compressed collagen gels (CCGs) in well-delimited areas, either in the center (inner-PA gels) or in the periphery (outer-PA gels). To achieve such precise spatial localization, a two-step process was adopted. Firstly, the central gels were prepared within $15.6 \mathrm{~mm} \emptyset$ wells of 24 -well plates (Greiner Bio-One) by mixing $0.9 \mathrm{~mL}$ of neutralized collagen solution with $0.1 \mathrm{~mL}$ of PA in SFM solution (for inner-PA gels) or SFM alone (for outer-PA gels), with or without hCSCs. Specifically, rat tail collagen type I $\left(2.05 \mathrm{mg} \mathrm{mL}^{-1}\right.$ in $0.6 \%$ acetic acid, First Link, UK) was mixed with $10 \times$ modified Eagle's minimum essential medium (Thermo Scientific) and sodium hydroxide $1 \mathrm{M}$ (Thermo Scientific) to form the neutralized collagen solution, which was then mixed with PA/SFM or SFM with and without cells $\left(1 \times 10^{5}\right.$ serum-starved hCSCs $\left.\mathrm{mL}^{-1}\right)$, in a 7:1:1:1 volume ratio, respectively. ${ }^{[28]}$ The central collagen gel solution was polymerized at $37^{\circ} \mathrm{C}$ in a humidified $5 \%$ $\mathrm{CO}_{2}$ incubator for $30 \mathrm{~min}$, and then gently removed from the molds, transferred into the center of a $22.1 \mathrm{~mm} \varnothing$ well of 12-well plates (Greiner Bio-One), and then surrounded by an identical collagen mixture $(0.9 \mathrm{~mL}$ of neutralized collagen solution and $0.1 \mathrm{~mL}$ of PA (for outer-PA gels) or SFM (for 
inner-PA gels). This mixture was then allowed to polymerize to obtain a composite gel with a seamless core-periphery interface and subsequently transferred in between layers of nylon mesh and compressed at room temperature with a $134 \mathrm{~g}$ or $154 \mathrm{~g}$ load (for gels with or without cells, respectively) for $5 \mathrm{~min}$ in sterile conditions. The resulting CCGs were then transferred to a 6-well plate (Greiner Bio-One) and cultured in +FBS or SFM up to 7 days with media changed every 2-3 days. All experiments were performed in an aseptic Class II cell culture cabinet.

Gel Contraction Assays: The rate of CCG contraction was monitored by digital photography every $24 \mathrm{~h}$, up to day 7 in culture, using a Nikon D90 digital camera (Nikon, Japan). Images were then analyzed using ImageJ v1.46, with three measurements of the gels' diameter to calculate tissue area and evaluate the average gel contraction in the different conditions, expressed as percentage decrease in surface area compared to the initial gel surface area. All experiments were performed three independent times, in triplicate $(n=3)$.

Live/Dead Double-Staining of Embedded Cells: To assess the viability of the encapsulated cells, the live/dead double staining using calcein-AM (Sigma Aldrich) and propidium iodide (PI; Sigma Aldrich) was performed following 7 days in culture according to the manufacturer's instructions. Briefly, functionalized CCGs were washed with PBS and incubated in the dark for $30 \mathrm{~min}$ at $37^{\circ} \mathrm{C}$ with PBS supplemented with calcein-AM and PI at $1 \mu \mathrm{M}$ ). The gels were then examined using a Axiovert 1 fluorescence microscope (Zeiss Microscopy, Germany) using the appropriate filter blocks to observe the presence of live (green) and dead (red-stained) cells. Fluorescence images were subsequently analyzed and merged using ImageJ v1.46. All experiments were performed in triplicate $(n=3)$.

Culture of hLESCs on Compressed Collagen Gels: Functionalized CCGs at day 5 of culture were mounted onto curved glass lenses $\left(13 \mathrm{~mm} \varnothing\right.$; contact angle: $\left.45^{\circ}\right)$ in 6 -well plates, pinned down 
using metal rings (inner Ø: $15 \mathrm{~mm}$; outer Ø: $25 \mathrm{~mm}$ ), and then were seeded with hLESCs on their top surface $\left(7.5 \times 10^{4}\right.$ cells per gel). The hLESCs were then cultured in CnT-7 medium for 10 days to evaluate their growth and phenotype in response to their different CCG substrates, and with medium change every 2-3 days.

In-Cell Western Blotting: The expression of protein markers from gel-encapsulated hCSCs was quantified following different culture conditions by near-infrared fluorescence analysis (in-cell Western blotting). Briefly, CCGs with or without cells cultured for 5 days were fixed with $2 \%$ paraformaldehyde (PFA) (Sigma Aldrich), washed twice in PBS, re-washed for 10 min in PBS supplemented with $0.25 \%$ Triton X-100 (PBS-T), and then incubated for $1 \mathrm{~h}$ with blocking solution (PBS-T with 5\% BSA) at room temperature. Subsequently, samples were incubated for $2 \mathrm{~h}$ with primary antibodies against $\alpha$ SMA (VPS281, Vector Labs, UK), $\alpha$ V $\beta 5$ integrin (ab24694, Abcam, UK) or keratocan (sc-66941, Santa Cruz Biotechnology, CA, USA) diluted 1:1,000 in blocking solution at room temperature. After three washes in PBS-T, samples were then incubated for $1 \mathrm{~h}$ at room temperature and with gentle agitation with corresponding anti-mouse or anti-rabbit IRDye 800-conjugated secondary antibodies and CellTag 700 cell marker (LI-COR Biotechnology, UK) diluted 1:25,000 in blocking solution. Subsequently, CCG samples were washed thrice in washing buffer and analyzed using the Odyssey CLx near-infrared system (LI-COR Biotechnology). Signals from each specific protein were quantified and normalized for the corresponding cell marker signal using Image J v1.46. Experiments were performed in triplicate $(n=3)$.

Confocal Immunofluorescence Analysis: Confocal microscopy was used to evaluate the arrangement of hCSCs within the various functionalized CCGs, as well as the phenotype of hLESCs grown on their surface. Briefly, CCGs with encapsulated hCSCs were fixed in 4\% PFA for $30 \mathrm{~min}$ at different time-points (from day 0 to day 7). After three washes with PBS for 5 min, samples were blocked for $1 \mathrm{~h}$ in PBS supplemented with 2\% BSA, incubated for $4 \mathrm{~h}$ with rabbit 
anti-collagen type I primary antibody (ab34710, Abcam) diluted 1:500 in blocking solution, washed thrice with PBS for $5 \mathrm{~min}$, and incubated for $2 \mathrm{~h}$ with Texas Red-conjugated goat anti-rabbit IgG antibody (TI-1000, Vector Labs), Alexa Fluor 488-conjugated phalloidin (Thermo Scientific), and DAPI (Thermo Scientific) diluted 1:1,000 in blocking solution. The gels were then washed three times with PBS for 5 min, mounted onto glass slides in glycerol (Sigma Aldrich) and imaged using an A1R confocal laser microscope (Nikon) with constant illumination and capture parameters. In particular, a Galvano scanner was used to acquire 2-5 $\mu \mathrm{m}$ thick $z$-stacks through the entire thickness of the sample using Nikon Plan Apo $\lambda 10 \times$ or $20 \times$ objectives (NA 0.45 or 0.75 , working distance 4 or $1 \mathrm{~mm}$, FOV $1.27 \times 1.27 \mathrm{~mm}$ or $0.64 \times 0.64 \mathrm{~mm}$, respectively). Micrographs were then analyzed using the NIS-Elements and ImageJ v1.46 software packages. Immunostaining and imaging of hLESCs grown on CCGs for 10 days was performed as described above, but using anti-CK3 (ab129910, abcam) with anti-CK15 (MA1-90929, Thermo Scientific), or anti-YAP (sc-17141, Santa Cruz Biotechnology) with anti- $\Delta$ p63 (sc-8431, Santa Cruz Biotechnology) primary antibodies diluted 1:500 in blocking solution. These samples were subsequently incubated with corresponding anti-mouse (TI-2000, FI-2000), anti-rabbit (FI-1000, Vector Labs), and anti-goat (sc-2783, Santa Cruz Biotechnology) secondary antibodies diluted 1:1,000 in blocking solution. Immunofluorescence analysis was performed three independent times, in triplicate $(n=3)$.

Atomic Force Microscopy (AFM): The topographical distribution of collagen fibrils in CCGs was analyzed by atomic force microscopy (AFM) using a Easyscan 2-controlled atomic force microscope (Nanosurf, Switzerland) equipped with ContAI-G soft contact mode cantilevers (BudgetSensors, Bulgaria) with a resonant frequency of $13 \mathrm{kHz}$ and nominal spring constant of 0.2 $\mathrm{N} / \mathrm{m}$.

Briefly, gels were fixed in 4\% PFA for 30 min at different time-points (from day 0 up to day 7), washed thrice with PBS, dried overnight over a glass slide (Bemis, USA) covered with three layers of parafilm (P7793, Sigma Aldrich) to minimize sample displacement and drift. Surface topography 
was analyzed in three separate regions per sample with $512 \times$ two-direction lines scanned at $10 \mu \mathrm{m}$ $\mathrm{s}^{-1}$, at $1 \mathrm{nV}$, and with P- and I-gains of 1 . Topographic data was processed for line wise and tilt correction using the Scanning Probe Image Processor software package (Image Metrology A/S).

Data was analyzed using the OrientationJ plugin from Image J v1.46 for measuring dimensions and distribution of specimens. Moreover, the stiffness of different samples was evaluated from 20 forcedistance curves acquired at $2 \mu \mathrm{m} \cdot \mathrm{s}^{-1}$ from different positions across each sample, and using AtomicJ 1.7.3 data analysis software for baseline and hysteresis correction, followed by elastic modulus calculation using the Sneddon sphere model, applicable for soft biological materials. All experiments were performed in triplicate on four individual areas in each sample $(n=3)$.

Analysis of the Hydration of Self-Curved Tissues: The weight of CCGs (with or without encapsulated cells) was measured immediately after compression and after culture to find their corresponding initial and final wet weight ( $W_{i}$ and $W_{f}$, respectively). For composite inner-PA and outer-PA CCGs, different samples were used for initial and final measurements, as gels were excised with a scalpel to separate their periphery and center regions, for each region to be weighted independently. The variation in wet weight $(\Delta W)$ was then expressed as the ratio $\Delta W=W_{f} / W_{i}$ (Equation 1). Subsequently, the percentage of water bound to the different CCGs was determined by freeze-drying (Christ, Alpha 1-2 LD plus) the gels to sublimate their frozen water from the solid to gas phase under controlled pressure. The dry weight $\left(W_{d}\right)$ of all freeze-dried gels was then measured, and used to calculate the hydration of CCGs using the formula for Hydration $(\%)=(1$ $\left.W_{d} / W_{i, f}\right) \times 100($ Equation 2).

Statistical Analysis: Differences between groups were determined using one- or two-way analysis of variance (ANOVA) with Bonferroni's multiple comparison post hoc test. Error bars represent the standard deviation of the mean. Significance between groups was established for $p<0.05,0.01$, 0.001 , and 0.0001 . 


\section{Supporting Information}

Supporting Information is available from the Wiley Online Library or from the author.

\section{Acknowledgements}

This work was supported by the Biotechnology and Biological Sciences Research Council

(BBSRC-UK), grant reference BB/N021576/1, Engineering and Physical Sciences Research

Council (EPSRC-UK), grant reference EP/L020599/1 and the Newcastle University Postgraduate

Studentship, award reference PHD/IHG/FT/8410F.

\section{Conflict of Interest}

The authors declare no conflict of interest.

\section{References}

[1] L. G. Griffith, G. Naughton, Science 2002, 295, 1009.

[2] T. van Manen, S. Janbaz, A. A. Zadpoor, Mater Today 2018, 21, 144.

[3] Q. Zhao, H. J. Qi, T. Xie, Progress in Polymer Science 2015, 49-50, 79.

[4] I. Apsite, G. Stoychev, W. Z. Zhang, D. Jehnichen, J. Xie, L. Ionov, Biomacromolecules 2017, 18, 3178.

[5] V. Stroganov, J. Pant, G. Stoychev, A. Janke, D. Jehnichen, A. Fery, H. Handa, L. Ionov, Adv Funct Mater 2018, 28.

[6] P. Q. Nguyen, N. M. D. Courchesne, A. Duraj-Thatte, P. Praveschotinunt, N. S. Joshi, Adv Mater 2018, 30.

[7] L. Ricotti, B. Trimmer, A. W. Feinberg, R. Raman, K. K. Parker, R. Bashir, M. Sitti, S. Martel, P. Dario, A. Menciassi, Sci Robot 2017, 2.

[8] S. J. Park, M. Gazzola, K. S. Park, S. Park, V. Di Santo, E. L. Blevins, J. U. Lind, P. H. Campbell, S. Dauth, A. K. Capulli, F. S. Pasqualini, S. Ahn, A. Cho, H. Y. Yuan, B. M. Maoz, R. Vijaykumar, J. W. Choi, K. Deisseroth, G. V. Lauder, L. Mahadevan, K. K. Parker, Science 2016, 353, 158.

[9] Y. Morimoto, H. Onoe, S. Takeuchi, Sci Robot 2018, 3.

[10] J. V. Jester, T. Moller-Pedersen, J. Huang, C. M. Sax, W. T. Kays, H. D. Cavangh, W. M. Petroll, J. Piatigorsky, Journal of cell science 1999, 112 ( Pt 5), 613.

[11] O. Kostyuk, O. Nalovina, T. M. Mubard, J. W. Regini, K. M. Meek, A. J. Quantock, G. F. Elliott, S. A. Hodson, The Journal of physiology 2002, 543, 633.

[12] K. M. Meek, D. W. Leonard, C. J. Connon, S. Dennis, S. Khan, Eye 2003, $17,927$.

[13] C. Boote, S. Dennis, Y. Huang, A. J. Quantock, K. M. Meek, Journal of structural biology 2005, 149, 1.

[14] S. A. Klein, R. B. Mandell, Investigative ophthalmology \& visual science 1995, 36, 2096.

[15] F. Li, D. Carlsson, C. Lohmann, E. Suuronen, S. Vascotto, K. Kobuch, H. Sheardown, R. Munger, M. Nakamura, M. Griffith, Proc Natl Acad Sci U S A 2003, 100, 15346.

[16] J. I. Kim, J. Y. Kim, C. H. Park, Sci Rep 2018, 8, 3424.

[17] A. Isaacson, S. Swioklo, C. J. Connon, Experimental eye research 2018, 173, 188. 
[18] W. Zhang, J. Chen, L. J. Backman, A. D. Malm, P. Danielson, Adv Healthc Mater 2017, 6.

[19] P. Fagerholm, N. S. Lagali, J. A. Ong, K. Merrett, W. B. Jackson, J. W. Polarek, E. J. Suuronen, Y. Liu, I. Brunette, M. Griffith, Biomaterials 2014, 35, 2420.

[20] H. J. Levis, J. Menzel-Severing, R. A. Drake, J. T. Daniels, Current eye research 2013, 38, 41.

[21] R. M. Gouveia, C. J. Connon, in Biomaterials and Regenerative Medicine in Ophthalmology (Second Edition), (Eds: T. V. Chirila, D. G. Harkin), Woodhead Publishing, 2016, 151.

[22] R. M. Gouveia, E. Koudouna, J. Jester, F. Figueiredo, C. J. Connon, Advanced Biosystems 2017.

[23] R. M. Gouveia, E. Gonzalez-Andrades, J. C. Cardona, C. Gonzalez-Gallardo, A. M. Ionescu, I. Garzon, M. Alaminos, M. Gonzalez-Andrades, C. J. Connon, Biomaterials 2017, 121, 205.

[24] R. M. Gouveia, V. Castelletto, I. W. Hamley, C. J. Connon, Tissue Eng Pt A 2015, 21, 1772.

[25] F. N. Syed-Picard, Y. Du, A. J. Hertsenberg, R. Palchesko, M. L. Funderburgh, A. W. Feinberg, J. L. Funderburgh, Journal of tissue engineering and regenerative medicine 2018, 12, 59.

[26] D. Karamichos, M. L. Funderburgh, A. E. Hutcheon, J. D. Zieske, Y. Du, J. Wu, J. L. Funderburgh, Plos One 2014, 9, e86260.

[27] N. Saeidi, K. P. Karmelek, J. A. Paten, R. Zareian, E. DiMasi, J. W. Ruberti, Biomaterials 2012, 33, 7366.

[28] R. M. Gouveia, R. R. Jones, I. W. Hamley, C. J. Connon, Biomater Sci-Uk 2014, 2, 1222.

[29] R. M. Gouveia, V. Castelletto, S. G. Alcock, I. W. Hamley, C. J. Connon, J Mater Chem B 2013, 1, 6157.

[30] A. J. Hughes, H. Miyazaki, M. C. Coyle, J. Zhang, M. T. Laurie, D. Chu, Z. Vavrusova, R. A. Schneider, O. D. Klein, Z. J. Gartner, Dev Cell 2018, 44, 165.

[31] M. P. Beales, J. L. Funderburgh, J. V. Jester, J. R. Hassell, Investigative ophthalmology \& visual science 1999, 40, 1658.

[32] S. E. Wilson, Experimental eye research 2012, 99, 78.

[33] N. Lakshman, A. Kim, W. M. Petroll, Experimental eye research 2010, 90, 350.

[34] M. A. Stepp, Experimental eye research 2006, 83, 3.

[35] E. C. Carlson, C. Y. Liu, T. I. Chikama, Y. Hayashi, C. W. C. Kao, D. E. Birk, J. L. Funderburgh, J. V. Jester, W. W. Y. Kao, J Biol Chem 2005, 280, 25541.

[36] C. Hahnel, S. Somodi, D. G. Weiss, R. F. Guthoff, Cornea 2000, 19, 185.

[37] W. M. Petroll, H. D. Cavanagh, J. V. Jester, Scanning 2004, 26, 1.

[38] B. Lee, X. Zhou, K. Riching, K. W. Eliceiri, P. J. Keely, S. A. Guelcher, A. M. Weaver, Y. Jiang, Plos One 2014, 9, e111896.

[39] W. R. Legant, J. S. Miller, B. L. Blakely, D. M. Cohen, G. M. Genin, C. S. Chen, Nat Methods 2010, 7, 969.

[40] H. C. Wells, K. H. Sizeland, N. Kirby, A. Hawley, S. Mudie, R. G. Haverkamp, J Mech Behav Biomed 2018, 79, 1.

[41] A. L. Plant, K. Bhadriraju, T. A. Spurlin, J. T. Elliott, Biochim Biophys Acta 2009, 1793, 893.

[42] J. W. Foster, R. R. Jones, C. A. Bippes, R. M. Gouveia, C. J. Connon, Experimental eye research 2014, $127,37$.

[43] R. R. Jones, I. W. Hamley, C. J. Connon, Stem Cell Res 2012, 8, 403.

[44] M. V. Netto, R. R. Mohan, S. Sinha, A. Sharma, W. Dupps, S. E. Wilson, Experimental eye research 2006, 82, 788.

[45] G. Pellegrini, E. Dellambra, O. Golisano, E. Martinelli, I. Fantozzi, S. Bondanza, D. Ponzin, F. McKeon, M. De Luca, Proc Natl Acad Sci U S A 2001, 98, 3156.

[46] A. Schermer, S. Galvin, T. T. Sun, The Journal of cell biology 1986, 103, 49.

[47] S. Dupont, L. Morsut, M. Aragona, E. Enzo, S. Giulitti, M. Cordenonsi, F. Zanconato, J. Le Digabel, M. Forcato, S. Bicciato, N. Elvassore, S. Piccolo, Nature 2011, 474, 179.

[48] V. Castelletto, R. M. Gouveia, C. J. Connon, I. W. Hamley, Faraday Discuss 2013, 166, 381. 

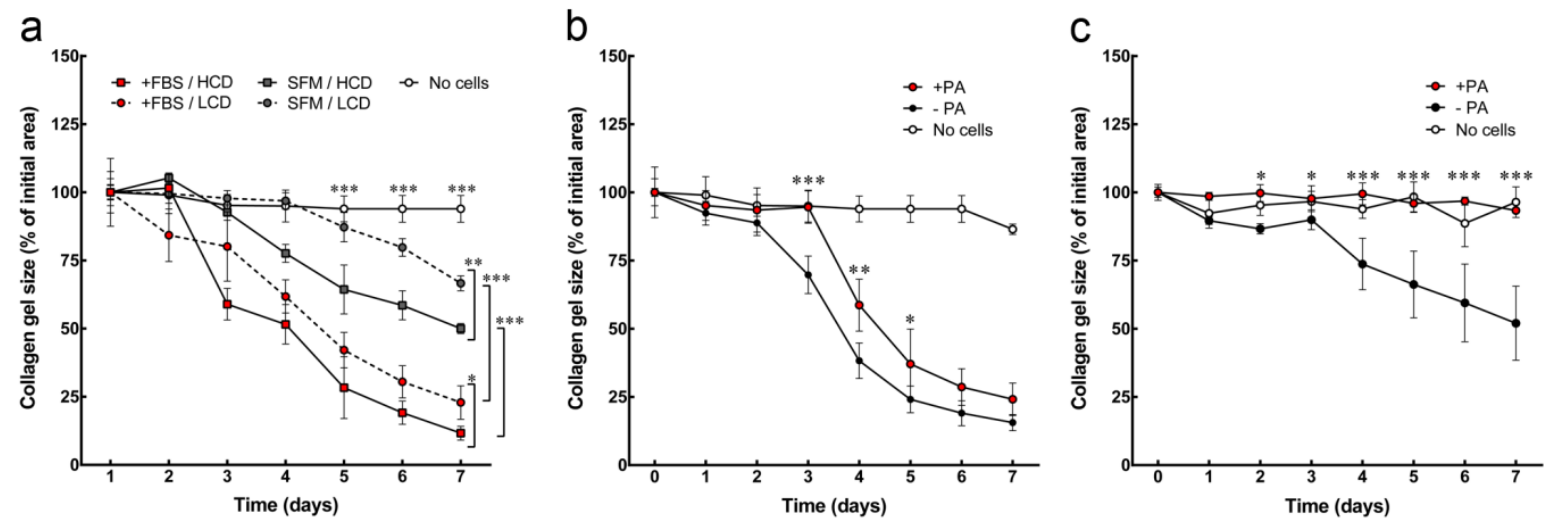

Figure 1: Effect of cell density, culture medium and PAs on gels contraction. (a) Size of CCGs (as percentage of corresponding initial area) in high (HCD) or low (LCD) cell density conditions, cultured in the presence (+FBS) or absence of serum (SFM). Measurements were performed daily, up to 7 days in culture. The inhibitory effect of PA on gel contraction evaluated both in (b) + FBS and (c) SFM conditions. Differences between average \pm S.D. area of gels with $(+\mathrm{PA})$ and without PA (-PA) were evaluated for each time point, in three independent experiments $(n=3) ; *$, ** and *** corresponded to $p<0.05,0.01$ and 0.001 , respectively. 

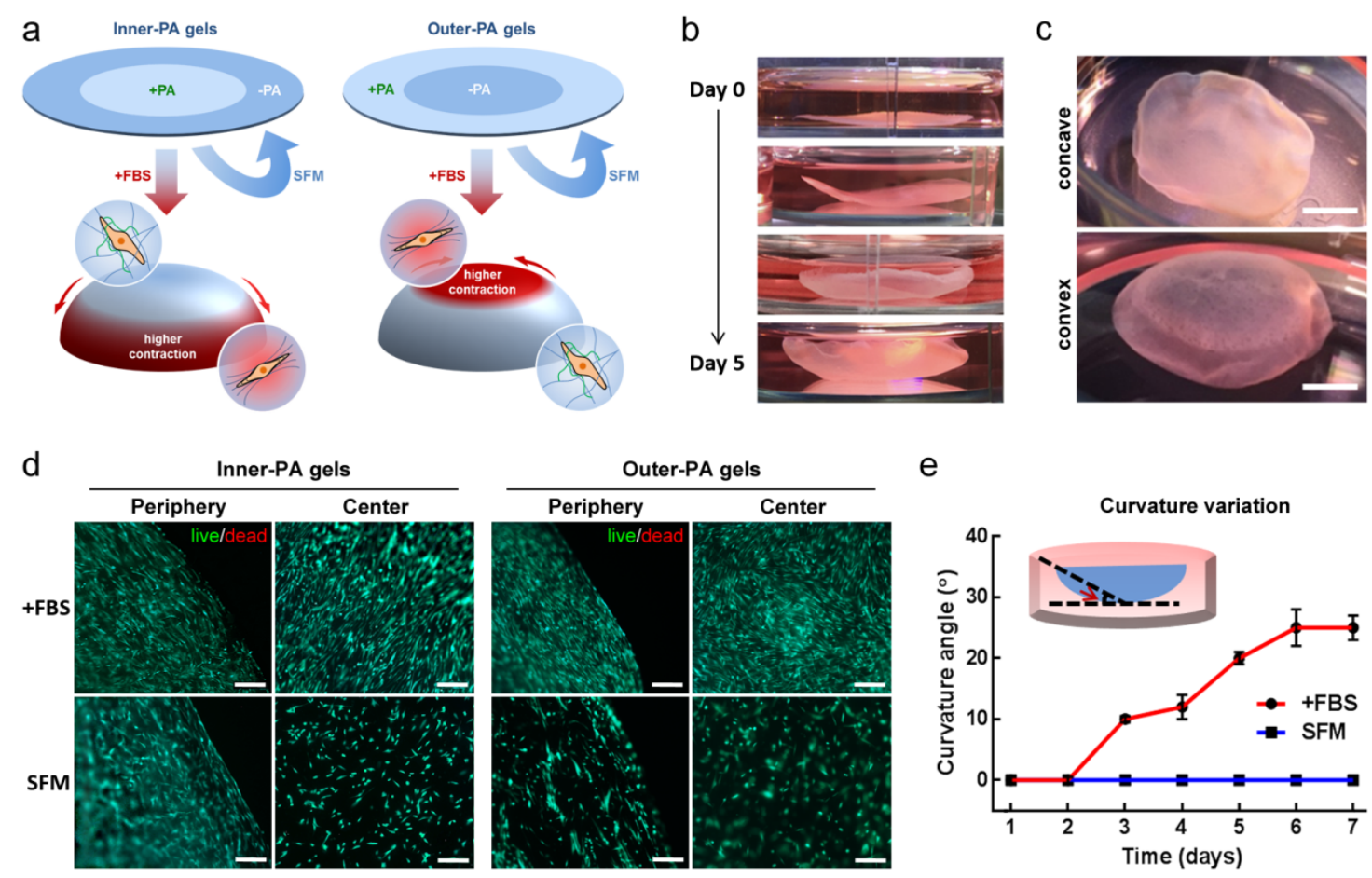

Figure 2: Shape-change and viability of composite CCGs over time. (a) Schematic of inner-PA and outer-PA CCG composition, and the predicted mechanism of differential gel contraction. In +FBS conditions (red arrows), cells within the $+\mathrm{PA}$ regions of CCGs contract less than in the regions without PA, thus driving gel self-curving; gels in SFM conditions (blue arrows) do not contract and retain shape. (b) Representative photographs of outer-PA CCGs self-curving when cultured for 5 days in presence of serum. (c) Representative photographs of self-curved concave and convex inner-PA CCGs. (d) Representative microphotographs of live (green)/dead (red)-stained hCSCs within composite CCGs after 7 days in +FBS and SFM culture conditions, showing a highly viable cell composition. (e) Variation of CCG curvature during a 7 day-culture in +FBS and SFM. Scale bars: $500 \mu \mathrm{m}(\mathrm{c})$ and $200 \mu \mathrm{m}(\mathrm{d})$. 

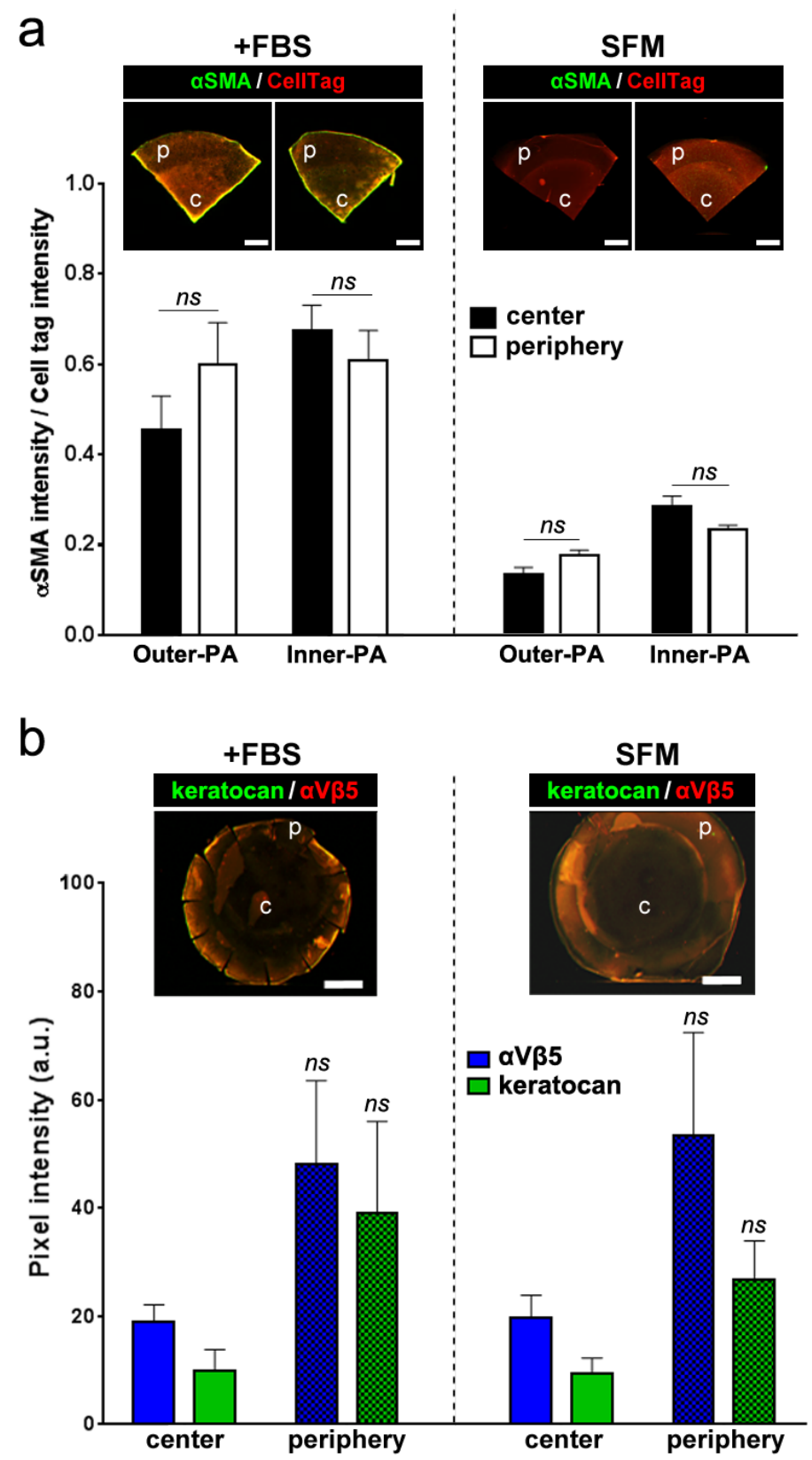

Figure 3: Effect of PAs on the expression of key markers of hCSCs in self-curved and planar constructs. (a) Expression of $\alpha$ SMA (normalized per intensity of the Cell Tag ${ }^{\mathrm{TM}}$ marker) by hCSCs encapsulated in the center $(c)$ and periphery $(p)$ of CCGs after 5 days of culture in the presence (+FBS) or absence of serum (SFM). (b) Expression of $\alpha \mathrm{V} \beta 5$ integrin and keratocan (as arbitrary unit) by hCSCs in outer-PA gels. Representative images are shown for each condition. Scale bars: $500 \mu \mathrm{m}$. 

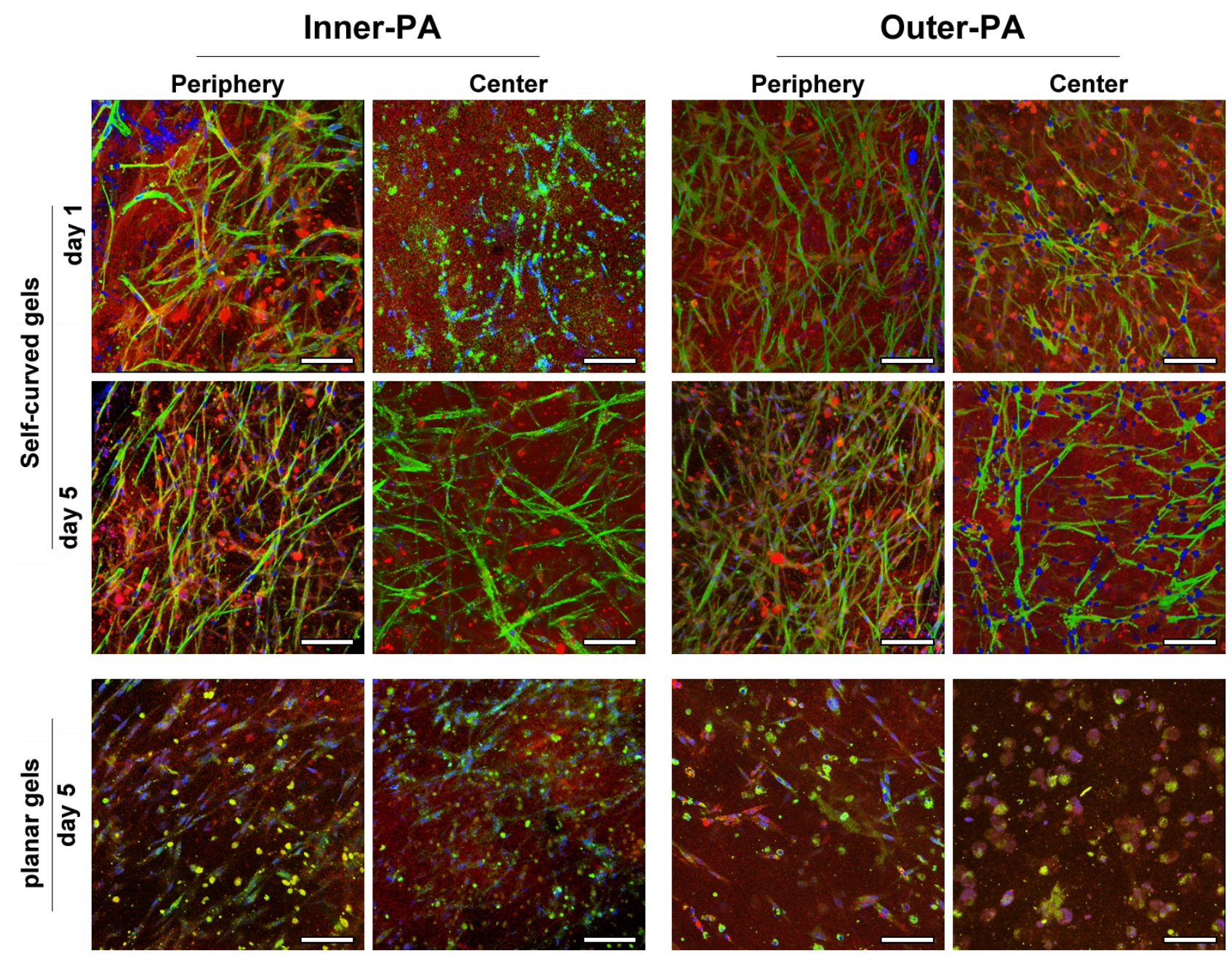

Figure 4: Organization of hCSCs within inner-PA and outer-PA gels. Representative 3D reconstruction of confocal immunofluorescence images of the periphery and center of CCGs acquired after 1 and 5 days in +FBS (self-curving gels) or SFM (planar gels). All the gels were stained for collagen I (red), F-actin (green, phalloidin) and nuclei (blue). Scale bars: $100 \mu \mathrm{m}$. 
a

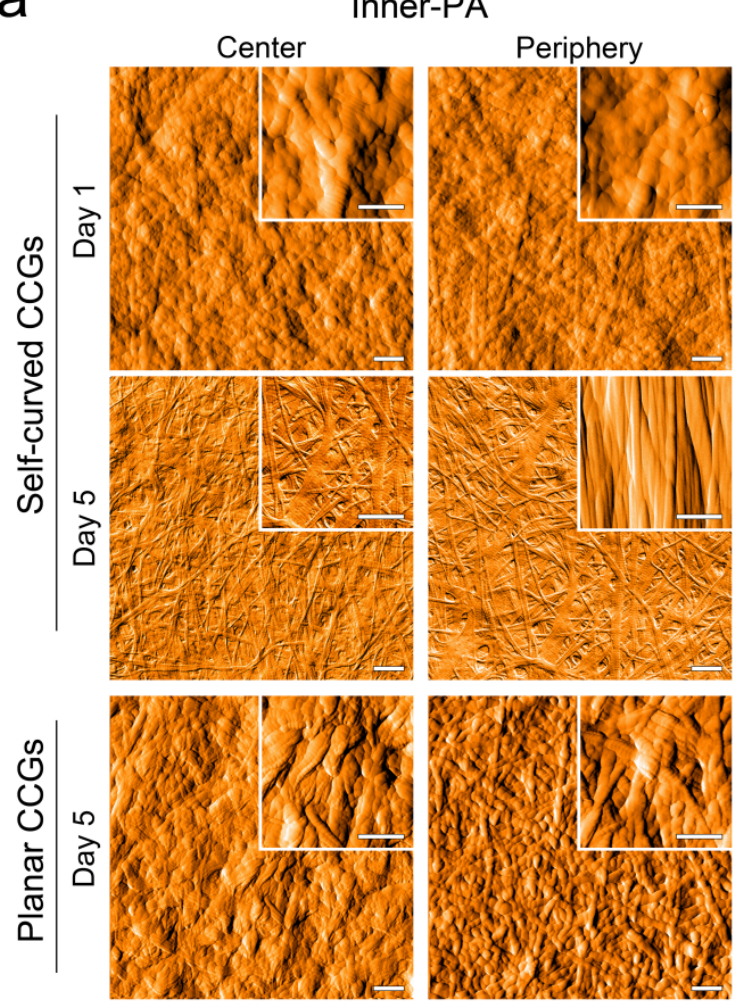

b

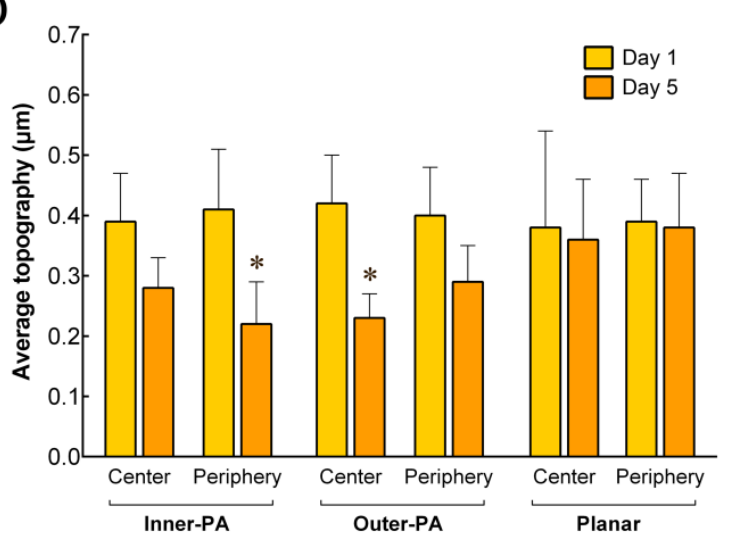

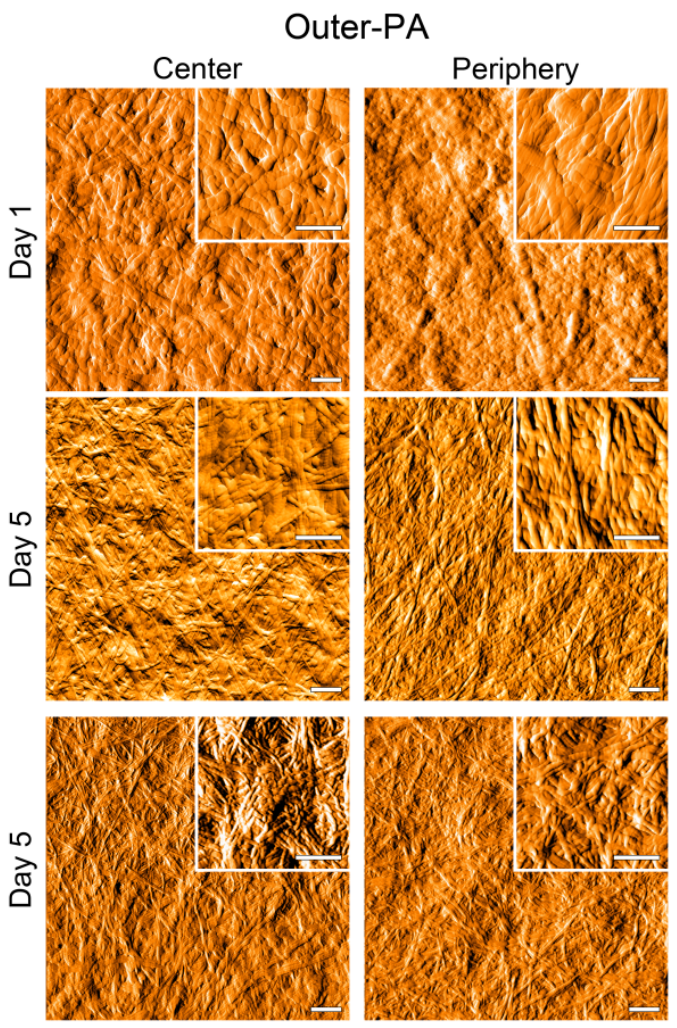

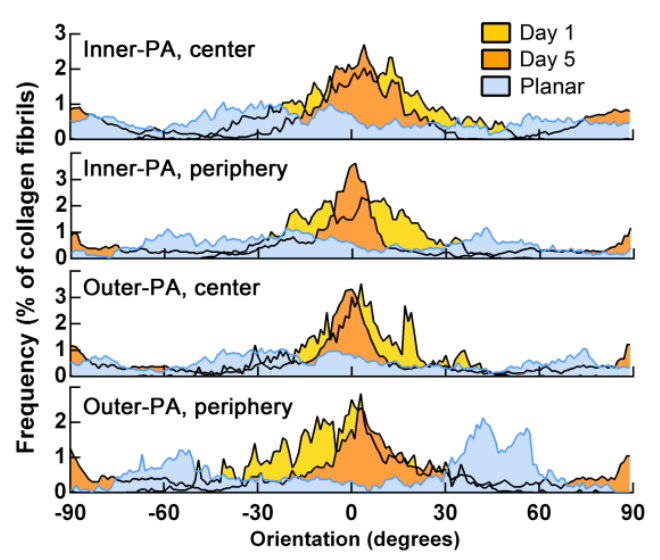

Figure 5: Topography of self-curving gels. (a) Representative atomic force microscopy (AFM) images of inner-PA and outer-PA CCGs after being cultured for 1 and 5 days in +FBS (self-curved CCGs) or SFM (planar CCGs). (b) CCG topography was quantified in terms of roughness (left) and collagen fibril orientation (right panels), with self-curving gels shown to acquire a more compact, ordered structure (narrowing of peaks) over time irrespective of the PA being loaded at periphery or center of CCG. Scale bars: $1 \mu \mathrm{m}, 0.2 \mu \mathrm{m}$ (insets). 

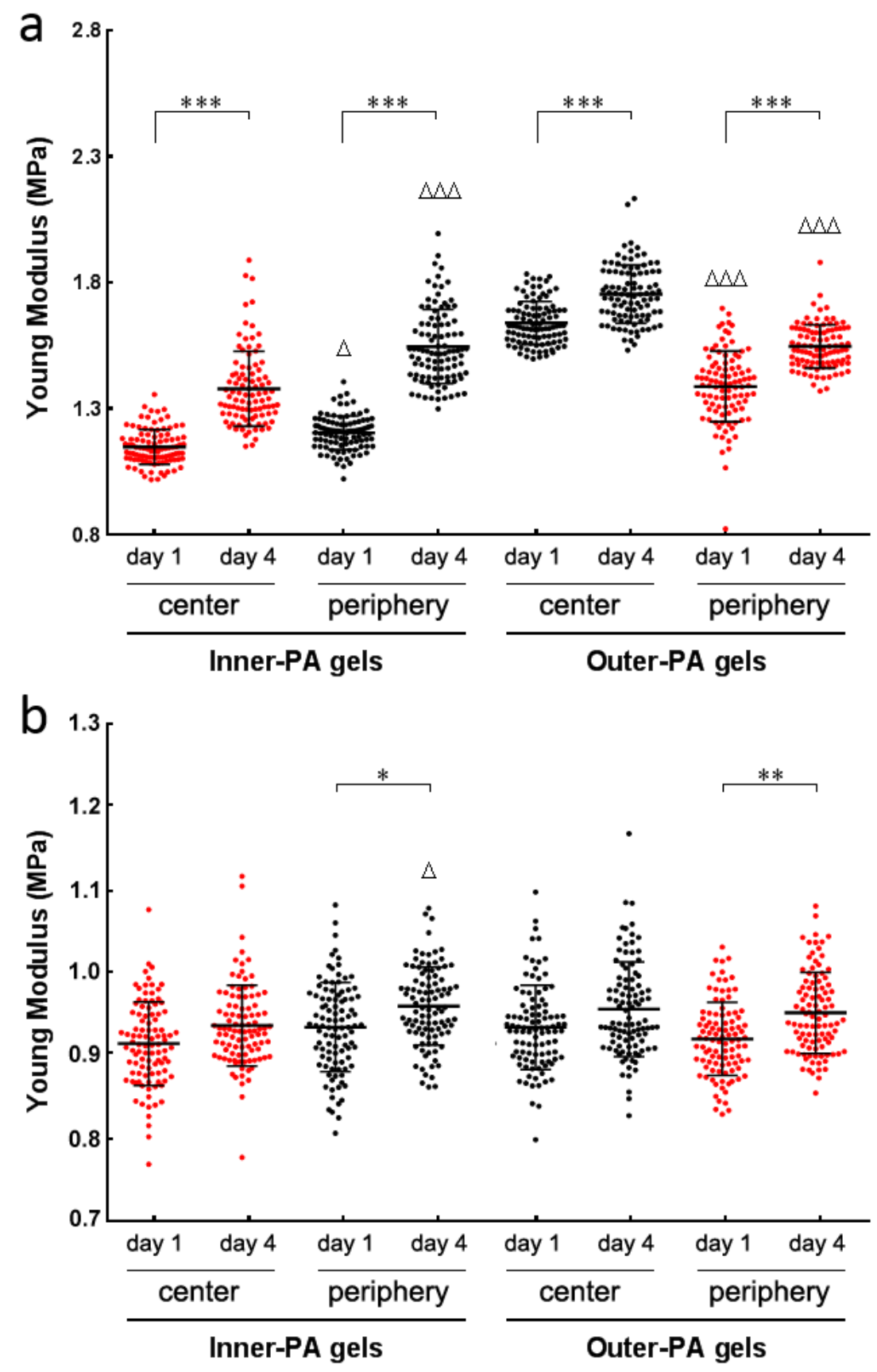

Figure 6: Mechanical properties of inner-PA and outer-PA gels. Graphs showing the stiffness of outer-PA and inner-PA gels after 4 days in culture either in +FBS (a) or in SFM condition (b) are reported. The colored points $(r e d)$ correspond to regions of the gel containing PA. Mean \pm S.D., $\mathrm{n}=$ 3 for all experiments; $*$ and $* * *$ referred to statistically significant differences between the same regions at different time points (effect of time) and corresponded to $p<0.05$ and 0.001 , respectively. ${ }^{\Delta}$ and ${ }^{\Delta \Delta \Delta}$ referred to statistically significant differences between different regions of the same gel for the same time point (effect of PA) and corresponded to $p<0.05$ and 0.001 , respectively. 
a

(i) Inner-PA gels (stiffer peripery)
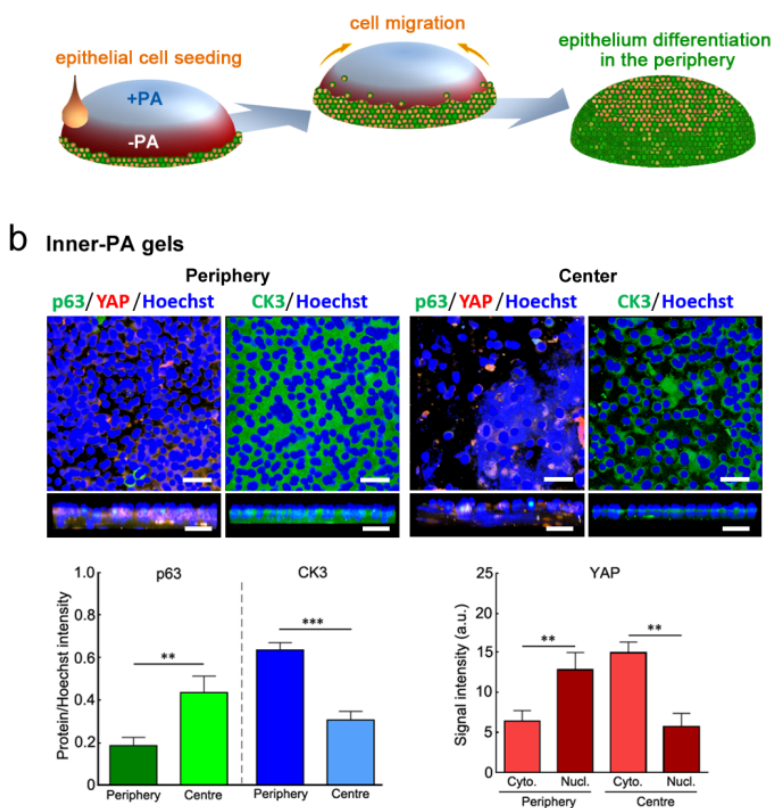

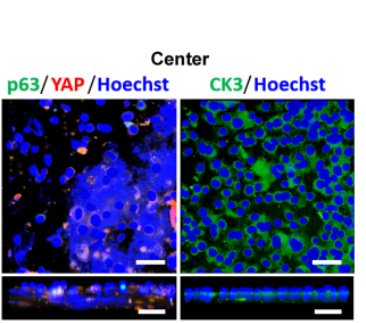

YAP

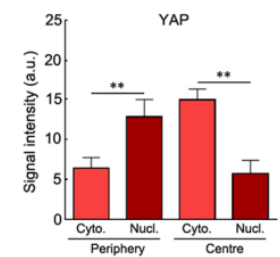

(ii) Outer-PA gels (stiffer center)

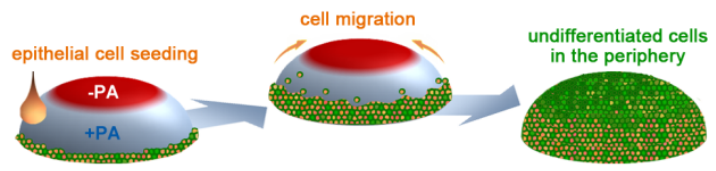

C Outer-PA gels
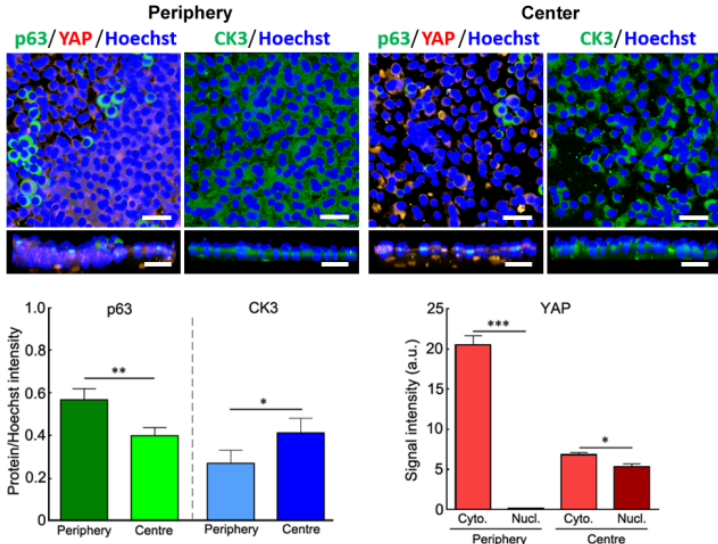

Figure 7: Self-curved CCGs used as substrates to support the growth and stratification of human limbal epithelial stem cells (hLESCs). (a) Schematic depicting the seeding, migration, growth and differentiation/stratification of hLESCs on self-curved (i) inner-PA and (ii) outer-PA gels. The impact of the substrate on the modulation of stem/progenitor cell (p63 and cytoplasmic YAP) and differentiation markers (CK3 and nuclear YAP) was evaluated by confocal immunofluorescence analysis (top and cross-section views) of both center and periphery of (b) inner-PA and (c) outer-PA CCGs after 10 days in culture. The detection of p63 (green)/YAP (red)/nuclei (blue), and of CK3 (green)/nuclei (blue) markers was quantified, with average \pm S.D. expression normalized to the intensity of nuclei signal in 10 independent gel locations $(n=1 ; *, * *$ and $* * *$ corresponded to $\mathrm{p}<$ $0.05,0.01$ and 0.001 , respectively). Scale bars: $50 \mu \mathrm{m}$. 